\title{
Piperine: A Remarkable Marker with Intense Biological
}

\section{Activity}

\author{
Gurinderdeep S* \\ Department of Pharmaceutical Sciences and Drug Research, Punjabi University, \\ Patiala, India
}

*Corresponding author: Gurinderdeep Singh, Department of Pharmaceutical

\section{Review Article \\ Volume 1 Issue 4}

Received Date: July 19, 2017

Published Date: November 16, 2017

Sciences and Drug Research, Punjabi University, Patiala, India, E-mail: gurinderdeep.singh@gmail.com

\section{Abstract}

Piperine, the main active constituent obtained from the black pepper belongs to family Piperaceae used as medicinal herb along with the spices which named as a "king of spices". Piperine chemically carries formula of C17H19NO3is a weak base and acquires a numerous medicinal properties. Principally, piperine showed intense biological activity as Antioxidant2, antitumor, antiasthmatics, antipyretic, analgesic, anti-inflammatory, antidiarrheal, anxiolytic, antidepressant, hepatoprotective, antibacterial, antifungal, anti-metastatic, anti-thyroid.

Keywords: Piper nigrum; P. longum; Piperine; Bioperine

\section{Introduction}

Black pepper (Piper nigrum), originated in the tropical evergreen forests of the Western Ghats of India named as 'the king of spice' or 'black gold' belonging to family Piperaceae. World widely, the largest producer of the Piper nigrum of production area $(1,77,340$ ha) with $55,000 \mathrm{t}$ in the aspects of IPC (2004) [1]. Black pepper (Piper nigrum), named as per the area in numerous way as Kalimirch in Urdu \& Hindi, Pipali in Sanskrit. Milagu in Tamil, Peppercorn, white pepper, Green Pepper Black pepper Madagascar pepper in English as reported. Traditionally, in biological systems numerous medicinal plants used due to its pharmaceutical potentials and lesser side effects. Along with medicinal properties black pepper can be used for various purposes such as various sauces \& dishes like meat dishes as well as in perfumery due to pungent alkaloids piperine (5-9\%) and volatile oils $(1-2.5 \%)$

Piperine, an active constituent found in Piper nigrum showsa numerous biological activity as Antioxidant, Antitumor, Antiasthmatics, Antipyretic, Analgesic, Antiinflammatory, Antidiarrheal, Anxiolytic, Antidepressant, Hepatoprotective, Antibacterial, Antifungal, Antimetastatic, Anti-thyroid [2-15].

\section{Pharmacognosy}

Black pepper of Piperaceae obtained from dried unripe fruits is a perennial herb which climbs and contains not less than $2.5 \%$ of piperine. Taxonomically, it can be classified in to

\author{
Kingdom - Plantae. \\ Class - Equisetopsida. \\ Subclass - Magnolidae. \\ Super Order-Magnoliane. \\ Order- Piperales. \\ Family - Piperaceae \\ Genus - Piper. \\ Species - Nigrum [16].
}

For the first time, 45 species of Piper were studied and reported by Hooker in 1886 but 29 species were from Indian origin. Afterwards, Rama Rao (1914) also enlisted 14 species of Piper from Western Ghats in his 'Flowering plants of Travancore'. Subsequently in 1921 again six species reported by Fisher from Annamalai hills and Fyson (1932) also reported four species as P. schmidtii \& P. wightii from Nilgiris \& Pulney hills top. Later on, in 1940 from Assam three more species were reported by Kangilal, et al. and after that Duthie P. longum, P. betle, $P$. mullesua, $P$. nepalense, \& P. nigrum from upper gangetic 
plains and adjacent Siwalic \& Sub Himalayan tracts which were reported in his flora in 1960. Recently Nirmal babu, et al. (1993), reported new five taxa of Piper from Kerala origin.

P. silentvalleyensis, $P$. nigrum var. hirtellosum $P$. pseudonigrum (Silent valley biosphere reserve) and $P$. sugandhagiri, Psugandhi var brevipillis (Sugandhagiri Cardamomplantation, wynad, Kerala)

Cytologically, all species of Piper with chromosomal number $2 n=24$ from the polyploidy series was studied by the Raliman \& Nair 1986 \& Samuel 1986 and also with basic chromosomal number $\mathrm{x}=13$ from South India and Sri Lanka origin and from north India $\mathrm{x}=12$.Single species as $P$. cubeba possess haploid number $\mathrm{n}=12$ as compared to previous chromosomal number $\mathrm{x}=13$ by Jose \& Sharma, 1985 [17].

In pharmacognosy facet the unripe berries of size approx. $5 \mathrm{~mm}$ of black pepper carries primarily as dietary fiber, calcium, magnesium, potassium, manganese, phosphorous and beta-carotene along with oleoresin and pepper oil. But basically, Piper nigrum species are rich of Vit $\mathrm{A}$ and $\mathrm{K}$.

Piperine $\left(\mathrm{C}_{17} \mathrm{H}_{19} \mathrm{O}_{3} \mathrm{~N}\right)$ (1- [5-(1-3, benzodioxal-5-yl)-1oxo-2, 4-pentadienyl Piperidine), obtained from Piper nigrum contains volatile oil, oleo resins \& alkaloids. Amongst alkaloids (piperine, chavicine, piperidine \& piperitine in majority) and starch (about 30\%) in lesser extent. Terpenes, steroids, lignans, flavones \& alkamides are the other primary constituents present in the Piper (Musenga, et al. 2007; murthy \& Bhattacharya, 2008). Later on, in Piper species aroma due to essential oils present, taste due to oleoresin and pungency due to its alkaloidal content piperine.

\section{Chemistry}

Piperine(1-[5-(1-3, benzodioxal-5-yl)-1-oxo-2,4pentadienyl Piperidine), confined first time by the Danish chemist Hans Christian or stedt in 1820 with molecular mass of $285.33 \mathrm{~g} / \mathrm{mol}$ contains carbon (71.55\%), nitrogen (4.91\%), oxygen (16. 82\%), Hydrogen (6.71\%).

As per physicochemical studies, it attains a yellow crystalline substance with melting point $\left(128-130^{\circ} \mathrm{C}\right)$ and insoluble in water physically. Chemically, Piperine is a weak base and exhibits hydrolysis nitric acid or aqueous alkali succumb to volatile base piperidine $\left(\mathrm{C}_{5} \mathrm{H}_{15} \mathrm{~N}\right)$ \& exhibited 4 isomeric forms. Normally Piperine is a tasteless, out of 4 isomeric forms, three forms are weakly pungent only. Chavicine, a stereo isomer delivers property of pungency to Black pepper. Practically, due to it's highly sensitivity to light so direct exposure avoided. Piperidine \& chavicine (a piperine \& its allied components) exhibits pungency to black pepper [18] (Figure 1).

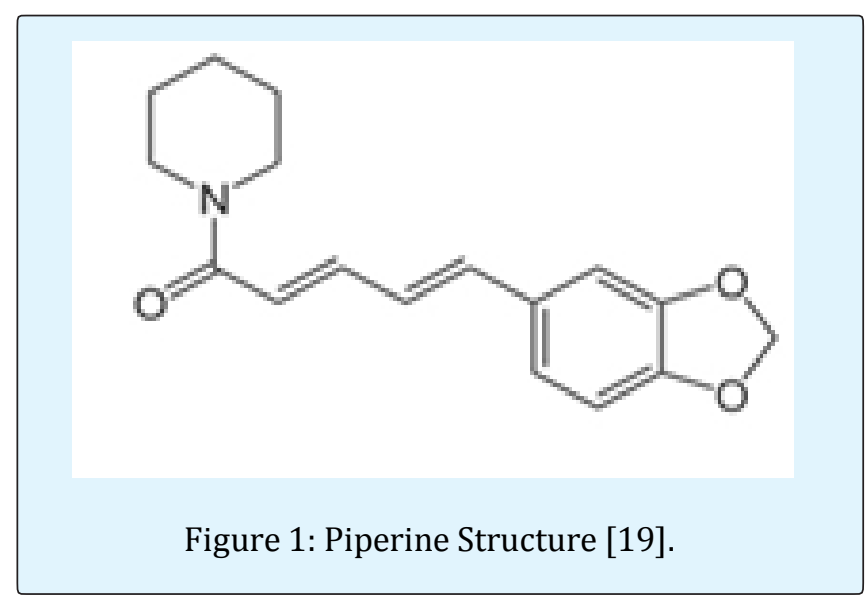

Chemically, piperine having chemical formula $\mathrm{C}_{17} \mathrm{H}_{19} \mathrm{NO}_{3}$ a weak base which upon acid or alkali hydrolysis decomposed in to two compounds named as piperidine $\left(\mathrm{C}_{5} \mathrm{H}_{11} \mathrm{~N}\right)$ and piperic acid $\left(\mathrm{C}_{12} \mathrm{H}_{10} \mathrm{O}_{4}\right)$. Structurally, piperine having trans-trans isomer while other isomers are cis-trans or trans-cis isomers and also others has no any pungency. In the pepper piperine gives pungent characteristic due to alkaloidal content in it.

\section{Pharmacological activities of Piperidine}

Piperdine, isolated from the Piper nigrum showed a number of pharmacological activities. Principally, Piper nigrum exhibited some important activities as:

- Antioxidant

- Anti-diarrheal

- Antimutagenic \& antitumor

- Anti-inflammatory

- Antiplatelet

- Analgesic

- Anti-hypertensive

- Hepatoprotective

- Anti-thyroid

- Antiasthmatic

- Cosmoperine

- Bioperine from P. nigrum [20]

\section{Anti-0xidant Activity of Piper Nigrum}

Oxidation is prerequisite step for the preservation of products. By the time gap, all products in the world whether they belong to natural \& synthetic deteriorated due to several factors. Antioxidant prevents the deterioration of products categorized under oxidizable products as food, cosmetics \& pharmaceuticals but efficacy, tendency and amount used varies as products. As concluded from 30years, spices reported many substances such as vitamins, flavonoids, terpenoids, 
carotenoids (carrots), phytoestrogens \& minerals found as active constituents in spices [20]. Gülçin İ, reported by comparing various extraction methods such as SOX, DPPH, ABTS \& UE for activity. In this study, DPPH method becomes irrelevant and SOX \& UE showed highest process yield [21]. Piper nigrum retards the induced stress (oxidative) by arresting the free radical production as well as inhibition of lipid peroxidation by considering enzymatically and nonenzymatically in rats as factor of oxidative stress in rats as reported by Vijayakumar, et al. [22].

\section{Anti-Diarrheal Activity}

As traditional concept the prevalence of disease affects two ways primarily of therapeutic potential and efficacy of drug as per the WHO. As per the age of exploration, Ayurvedic medicine and theirs spices heals the disease naturally as they having the therapeutic potential. In the todays modern world, in developing countries the leading cause mortality and morbidity due to disease is diarrhea. The use of castor oil and magnesium sulphate in aqueous black pepper extract to treat diarrhea in mice through antimotility and antisecretory activity as reported by Prashant B. Sham Kumar, et al. [7].

\section{Anti-Tumor}

From the primordial times also drugs related to the naturally derived compounds are used used to treat the tumours in various parts of the body as seen in Vinca, Piperidine, etc. By the refluxing the alkaloid piperidine purification done and showed $51.38 \%$ of inhibition of tumour at $5 \mu \mathrm{g} / \mathrm{ml}$ concentration. In the ethanolic extract of Piper nigrumsix alkaloidal bands reported and then purified by S.K. Reshmi, E. Sathya \& P. Suganya Devi [23].

\section{Analgesic and epileptic}

In traditional medicines, various drugs used but black pepper has been extensively used in various purposes as analgesic, anti-inflammatory as well as epileptics. Bukhari IA, et al. reported these effects in vivo in mice study by administering drug against standard (Valproic acid $(200 \mathrm{mg} / \mathrm{kg})$, carbamazepine $(30 \mathrm{mg} / \mathrm{kg})$ \& diazepam $(1 \mathrm{mg} / \mathrm{kg})$ ) intraperitoneally (i.p.). In the study, they found piperine with significant delay on the onset of PTZ \& PIC (Pentylene tetrazole \& Picrotoxin) in mice and showed piperine exhibits pain as well as epilepsy properties [5].

\section{Hepatoprotective effect of $P$. nigrum}

As a hepatoprotector Piper nigrum also reported after silybum marianum experimentally, on animal models \& in humans. Matsuda, et al. determined in mice treated with D-galactosamine that induced the liver toxicity profile in mice when exposed to the dose dependent piperine. Which inhibited increase in serum GPT \& GOT levels and further suggested the inhibitory effects that depended mainly on the reduced sensitivity of hepatocytes to TNF- $\alpha$ [24].

\section{Anti-asthmatics}

Traditionally, Indian medicines and in pacific islands pepper from Piperaceae family Piper longum is slender climbing and glabrous plant carries piperine and piperlongumine as a major active constituent which shows antiasthamatic activity along with other activities. Many herbal practioners believed with the addition of black pepper in to the green tea (antioxidant, anticancer \& soon) relieves the asthma as per literature review. Kim, et al. studied with different proportions the effects of piperine suppressed that infiltration of eosinophyl, hyper responsiveness also reduced and with the production of histamine, interlukin-5, IG-E \& IL-4 significantly inflammation supresssess [25].

\section{Anti-inflammatory Activity}

Bang Jun Soo et al studied the inhibitory effects of piperine with reduction of IL6, MMP 13 and PGE production at different concentrations starting from 10 to $100 \mu \mathrm{g} / \mathrm{ml}$ but reduction in the production of $\mathrm{PGE}_{2}$ at minimal dose. At some concentrations, activator protein 1(AP-1) migration also reduced due to the inhibitory activity if the piperine on clinical testing in rats and shown by the histological staining that piperine carries strong anti-inflammatory activity [6].

\section{Bioperine}

Bioperine, natural black pepper extract containing more than $95 \%$ piperine the active constituent of the pepper to enhance the health and wellness after the standardization of the fruits of it [26]. Bioperine a specific product carries pure alkaloidal content obtained from the Piper nigrum. Presently, study conducted for the evaluation of the piperine potential by enhancing the serum response from the fat-soluble nutrients named as pro-vitamin beta-carotene [27].

\section{Conclusion}

Black pepper is the "king of spices" and "real gold" used traditionally from the ayurvedic periods. The active constituent of the black pepper is the piperine along with alkaloids, olefins, fibers and other constituents. The content of piperine in the black pepper is more than 95 $\%$ by showing numerous biological activities and used in clinical purposes. Nowadays, present research carried out and extracted out a bioperine as a natural black pepper extract and having piperine as main active constituent in it as well as standardized out for the wellness of health. 


\section{References}

1. Sivaraman K, Kandiannan K, Peter KV, Thankamani CK (1999) Agronomy of black pepper (Piper nigrum L.)-a review. Journal of Spices and Aromatic Crops 8(1): 1-18.

2. Sortino J, Agbor GA, Akinfiresoye L, Johnson R, Vinson JA (2012) Piper species protect cardiac, hepatic and renal antioxidant status of atherogenic diet fed hamsters. Food Chem 134(3): 1354-1359.

3. Selvendiran K, Sakthisekaran D (2004) Chemopreventive effect of piperine on modulating lipid peroxidation and membrane bound enzymes in benzo(a) pyrene induced lung carcinogenesis. Biomed Pharmacother 58(4): 264-267.

4. Verma S, Parganiha R, Chandrakar S, Pal S, Sawarkar HA, et al. (2011) In vitro anti- asthmatic activity of fruit extract of Piper nigrum (Piperaceae). Inter J Herbal Drug Res 1: 15-18.

5. Pivac N, Bukhari IA, Alhumayyd MS, Mahesar AL, Gilani AH (2013) The analgesic and anticonvulsant effects of piperine in mice. J PhysiolPharmacol 64(6): 789-794.

6. Choi HM, Bang JS, Oh da H, Sur BJ, Lim SJ, et al. (2009) Anti-inflammatory and antiarthritic effects of piperine in human interleukin 1beta-stimulated fibroblast-like synoviocytes and in rat arthritis models. Arthritis Res Ther 11(2): R49.

7. Shahi SR, Shamkuwar PB, Jadhav ST (2012) Evaluation of antidiarrhoeal effect of Black pepper (Piper nigrum L). Asian Journal of Plant Science and Research 2(1): 48-53.

8. Srinivasan K, Platel K (2001) Studies on the influence of dietary spices on food transit time in experimental rats. Nutr Res 21(9): 1309-1314.

9. Xian YF, Mao QQ, Huang Z, Zhong XM, Ip SP (2014) Piperine reverses the effects of corticosterone on behavior and hippocampal BDNF expression in mice. NeurochemInt 74: 36-41.

10. Bapat AR, Nirwane AM (2012) Effect of methanolic extract of Piper nigrum fruits in Ethanol-CCl4 induced hepatotoxicity in Wistar rats. Der Pharmacia Lettre 4: 795-802.

11. Siddiqui M, Khan M (2007) Antimicrobial activity of Piper fruits. Nat prod Rad 6(2): 111-113.

12. Vanaja M, Kumar KP, Gnanajobitha G, Kumar SR, Malarkodi C, et al. (2014) Piper nigrum Leaf and Stem Assisted Green Synthesis of Silver Nanoparticles and Evaluation of its Antibacterial
Activity against Agricultural Plant Pathogens. Scientific World Journal 2014: 829894.

13. Simhan J, Makhov P, Golovine K, Canter D, Kutikov A, et al. (2012) Co-administration of piperine and docetaxel results in improved anti-tumor efficacy via inhibition of CYP3A4 activity. Prostate 72(6): 661667.

14. Qu KP, Chen CY, Li W, Chen CR (2013) Piperine exerts anti-seizure effects via the TRPV1 receptor in mice. Eur J Pharmacol 714(1-3): 288-294.

15. Kar A, Panda S (2003) Piperine lowers the serum concentration of thyroid hormones, glucose and hepatic 5'D activity in adult male mice. Horm Metab Res 35(9): 523-526.

16. Zoheir A, Damanhouri, Aftab Ahmad (2014) "A Review on Therapeutic Potential of Piper nigrum L." Black Pepper): The King of Spices. Medicinal \& Aromatic Plants 3(3): 1-6.

17. Justin CGL, Thangaselvabal T, Leelamathi M (2008) Black pepper (Piper nigrum l.) 'THE KING OF SPICES'-a review. Agric Rev 29(2): 89-98.

18. Chandra D, Yadav KK, Singh VK, Patel A, Chaurasia S (2014) An Overview: The Novel Carrier For Vesicular Drug Delivery System. World Journal of Pharmaceutical Research 3(6): 1299-1322.

19. Upender M, Vasavirama K (2014) Piperine: A Valuable Alkaloid from Piper Species. Int J Pharm Pharm Sci 6(4): 34-38.

20. Khan MA, Fazal H, Abbasi BH, Farooq S, Ahmad N, et al. (2012) Biological role of Piper nigrum L.(Black pepper): A review. Asian Pacific Journal of Tropical Biomedicine 2(3): 1945-1953.

21. Gülçin İ (2005) The antioxidant and radical scavenging activities of black pepper (Piper nigrum) seeds. Int J Food Sci Nutr 56(7): 491-499.

22. Surya D, Vijayakumar RS, Nalini N (2004) Antioxidant efficacy of black pepper (Piper nigrum L.) and piperine in rats with high fat diet induced oxidative stress. Redox Rep 9(2): 105-110.

23. Sathya E, Reshmi SK, Devi PS (2010) Isolation of piperdine from Piper nigrum and its antiproliferative activity. J Med Plant Res 4(15): 1535-1546.

24. Singh A, Duggal S (2009) Piperine-review of advances in pharmacology. Int $J$ Pharm Sci Nanotechnol 2(3): 615-620. 
25. Goswami TK, Meghwal M (2013) Piper nigrum and piperine: an update. Phytother Res 27(8): 11211130.

26. BioPerine
27. Vladimir B, Muhammed M, Edward PN (1999) Piperine, an alkaloid derived from black pepper increases serum response of beta-carotene during 14-days of oral beta-carotene supplementation. Nutrition Research 19(3): 381-388. 